\title{
The effects of BMMSC treatment on lung tissue degeneration in elderly macaques
}

\author{
Yu-kun Yang ${ }^{1,2,3,4+}$, Ye Li $i^{1,2,3,4+}$, Yan-ying Wang ${ }^{1,2,3}$, Guang-ping Ruan ${ }^{1,2,3}$, Chuan Tian ${ }^{1,2,3}$, Qiang Wang ${ }^{1,2,3}$, \\ Huan-yu He ${ }^{4}$, Gao-hong Zhu' ${ }^{5}$, Dong Fang ${ }^{5}$, Mao Wang ${ }^{5}$, Xiang-qing Zhu ${ }^{1,2,3,4^{*}}$ and Xing-hua Pan ${ }^{1,2,3,4^{*}}$
}

\begin{abstract}
Background: Age-associated lung tissue degeneration is a risk factor for lung injury and exacerbated lung disease. It is also the main risk factor for chronic lung diseases (such as COPD, idiopathic pulmonary fibrosis, cancer, among others). So, it is particularly important to find new anti-aging treatments.

Methods: We systematically screened and evaluated elderly senile multiple organ dysfunction macaque models to determine whether BMMSCs inhibited lung tissue degeneration.

Results: The average alveolar area, mean linear intercept (MLI), and fibrosis area in the elderly macaque models were significantly larger than in young rhesus monkeys $(p<0.05)$, while the capillary density around the alveoli was significantly low than in young macaque models $(p<0.05)$. Intravenous infusion of BMMSCs reduced the degree of pulmonary fibrosis, increased the density of capillaries around the alveoli $(p<0.05)$, and the number of type II alveolar epithelium in elderly macaques $(p<0.05)$. In addition, the infusion reduced lung tissue ROS levels, systemic and lung tissue inflammatory levels, and Treg cell ratio in elderly macaque models $(p<0.05)$. Indirect co-cultivation revealed that BMMSCs suppressed the expression of senescence-associated genes, ROS levels, apoptosis rate of aging type II alveolar epithelial cells (A549 cells), and enhanced their proliferation $(p<0.05)$.
\end{abstract}

Conclusions: BMMSC treatment inhibited age-associated lung tissue degeneration.

Keywords: BMMSCs, Lung degeneration, Type II alveolar epithelial cells, Macaque

\section{Introduction}

The rising aging population in China is a risk for various diseases. It is estimated that by 2050 , those aged 65 years and above will represent about $20 \%$ of the Chinese population [1]. Age enhances structural changes of the respiratory system, including a gradual increase in lung tissue degeneration, alveolar enlargement, alveolar wall destruction, reduced gas exchange surface area, increased airway obstruction or occlusion, decreased pulmonary vascular density, increased collagen deposition,

\footnotetext{
* Correspondence: qing1021zhu@163.com; xinghuapan@aliyun.com

${ }^{\dagger}$ Yu-kun Yang and Ye Li contributed equally to this work.

'Kunming Key Laboratory of Stem Cell and Regenerative Medicine, 920th

Hospital of the PLA Joint Logistics Support Force, Kunming 650032, Yunnan Province, China

Full list of author information is available at the end of the article
}

and decreased elastin, etc. [2-4] Immune system disorders such as non-specific inflammation and suppressed immune responses, etc. [5], functional changes such as loss of elastic recoil, increased residual volume, and gas exchange barriers $[2,6]$ enhance lung tissue susceptibility to injury. The injuries lead to the development of chronic lung diseases such as COPD, idiopathic pulmonary fibrosis, and cancer [7]. Therefore, there is a need to develop options for inhibiting aging-associated lung degenerative changes.

Mesenchymal stem cells are multipotent stem cells. They are characterized by low immunogenicity, selfrenewal ability, and multi-directional differentiation potential. Due to immune-associated regulation of antiapoptosis, angiogenesis, migration and differentiation of 
stem cells in target organs, enhancing the growth and differentiation of local stem cells, progenitor cells and antiscarring have been used in the treatment of various diseases [8].

Studies have documented that mesenchymal stem cells can repair lung injuries and effectively treat acute and/or chronic lung diseases [9-11]. However, a majority of these studies have been performed on rodents with a few of them being performed on primates. Moreover, the efficacy of mesenchymal stem cells in age-associated lung tissue degeneration has not been established.

Macaques are popular non-human primates whose biological characteristics are identical to those of humans. As model organisms, macaques are physiologically identical to humans. Their genomes have a $93 \%$ average sequence identity with humans. They are, therefore, ideal models for studies of human health and disease.

In addition, as model animals for basic and applied research in biomedicine, macaques have numerous advantages including environmental factor control and ease of scale $[12,13]$.

Therefore, the aim of this study was to determine the in vivo and in vitro effects of bone marrow mesenchymal stem cells (BMMSCs) on age-associated lung tissue degeneration.

\section{Materials and methods}

\section{Animal and cell sources}

Thirty macaques aged between 2 and 26 years and weighing $2.2-12 \mathrm{~kg}$ were obtained from the Kunming Institute of Zoology of the Chinese Academy of Sciences [SCXK (Yunnan) K2017-0003]. Among them, 25 were female macaques aged between 6 and 26 years while 5 were male macaques aged between 2 and 3 years. The animals were housed in the Experimental Animal Center of the 920th Hospital of the Chinese People's Liberation Army Joint Logistics Support Force, experimental animal license number: SYXK (Military) 2017-0051. Ethical approval for the use of animal models was obtained from the experimental animal council of the 920th Hospital of Joint Logistics Support Force.

Bone marrow A549 cell lines were purchased form the Wuhan Sevier company, sub-cultured in a culture flask with DMEM medium supplemented with $10 \%$ fetal bovine serum. They were then incubated at $37^{\circ} \mathrm{C}$ in an atmosphere of $5 \%$ carbon dioxide.

\section{Main reagents and antibodies}

FBS and penicillin-streptomycin solution were purchased from Servicebio; DMEM/F12 media was purchased from Hyclone; $0.25 \%$ pancreatin-0.04\% EDTA was purchased from Invitrogene; 30\% hydrogen peroxide solution was purchased from Solarbio; Cell senescence $\beta$-galactosidase staining kit, apoptosis detection kit, active oxygen detection kit, and cell cycle and apoptosis detection kit were purchased from Beyotime Biotechnology; AntiproSP-C antibody (AB3786) was purchased from Sigma; Mouse anti-human CD45 (555555), mouse anti-human CD73 (344007), Cell staining buffer, True-Nuclear Transcription Factor Buffer Set, Alexa Fluor 647 anti-human FoxP3 (320113), FITC anti-human CD4 (317408), PE anti-human CD25 antibody (356103), PE Mouse IgG1 k Isotype Ctrl and Alexa Fluor 647 Mouse IgG1 k Isotype Ctrl (400135) were purchased from Biolegend; monkey interleukin $1 \beta$ (IL-1 $\beta$ ), monkey interleukin-17A (IL-17A), and human tumor necrosis factor alpha (TNF- $\alpha$ ) ELISA kits were purchased from MeiMian; fluorescent secondary antibody HRP, fluorescent secondary antibody CY3, and primers were purchased from Servicebio; GoScriptTMReverse Transcription System and GoTaq ${ }^{\circ}$ PCR Master Mix were purchased from Promega Corporation; TNF alpha (7B8A11), IL-10 (20850-1-AP), and CEBPB (2B6E10) antibodies were purchased from Proteintech group; adipogenic differentiation medium, osteogenic differentiation medium, and chondrogenic differentiation medium were purchased from Guangzhou Saiye Biological Technology Co., Ltd.; ${ }^{18}$ F-FDG was provided by the First Affiliated Hospital of Kunming Medical University.

\section{Experimental protocols}

\section{Screening and evaluation of senile lung degeneration} macaque models

Female macaques aged between 22 and 26 years were used as the elderly model group, while young female macaques aged between 6 and 8 years old were used as the control group. A total of 5 animals were randomly distributed in each group. Five milliliters of peripheral blood was obtained from cynomolgus monkeys and centrifuged to obtain serum. Lung length and width were determined using a ruler. Serum samples were used to quantify TNF- $\alpha$ and IL-1 $\beta$ levels through the ELISA technique. Macaques were anesthetized with $3 \%$ pentobarbital sodium $(5 \mathrm{ml} / \mathrm{kg}$ body weight) and sacrificed to obtain lung tissues. Tissue samples were divided for size, morphology, and textural analysis as well as hematoxylin-eosin staining. The Masson's Trichrome stain was used to determine the degree of pulmonary fibrosis in the two groups. Capillary density was examined by immunohistochemistry.

\section{Preparation and identification of macaque bone marrow mesenchymal stem cells}

Bone marrow mesenchymal stem cells of 2-3-year-old young rhesus monkeys were isolated and cultured by the adherence method. The morphology and growth characteristics of P4 BMMSC generation cells were observed while CCK8 was used to determine their proliferative capacities. A flow cytometer was used to analyze the positive rate of their surface antigens. A special 
induction medium was used to induce the differentiation of P4 BMMSCs into bone, cartilage, and adipocytes. Their differentiation abilities were analyzed by staining (shown in supplementary file 1).

\section{Cell processing and injection}

When the fusion degree of the cultured P4 BMMSC generation was over $80 \%$, the cells were digested and washed. They were diluted with $0.9 \%$ sterile sodium chloride solution at a concentration of $2 \times 10^{6}$ cells $/ \mathrm{ml}$. After the macaques had been fixed, the BMMSCs were infused in their femoral veins at a cell dose of $1 \times 10^{7}$ cells $/ \mathrm{kg}$ per macaque, once every other day, for a total of 3 infusions. The macaques in the control and model groups were also administered with equal volumes of $0.9 \%$ sterile sodium.

\section{Determination of the histological structure of macaque lung} tissues after BMMSC infusion

Lung tissue changes were determined by PET-CT before BMMSC treatment and at 90 as well as 180 days after treatment. After 180 days of treatment, the macaques were anesthetized and sacrificed. Lung tissues were obtained and histologically analyzed (as show in supplementary file 1).

\section{Determination of the effects of BMMSCs on type II alveolar epithelial cells}

A549 cell lines were cultured in complete mediums supplemented with $200 \mu \mathrm{mol} / \mathrm{L}, 400 \mu \mathrm{mol} / \mathrm{L}, 600 \mu \mathrm{mol} / \mathrm{L}$, $800 \mu \mathrm{mol} / \mathrm{L}, 1000 \mu \mathrm{mol} / \mathrm{L}$, and $1200 \mu \mathrm{mol} / \mathrm{L}$ hydrogen peroxide. The expression levels of the P53 gene were determined by PCR while $\beta$-galactosidase staining was performed to determine the optimal hydrogen peroxide concentrations. The expression levels of TERT, TCAB1, P53, and P21 were quantified by RT-PCR using the GoScriptTM Reverse Transcription System and GoTaq ${ }^{\circ}$ PCR Master Mix according to the manufacturer's instructions. The expression of these genes reflected A549 cell senescence levels at specific hydrogen peroxide concentrations. A senescence model of type II alveolar epithelial cell was established. Senescent cells were seeded in the lower chamber of a transwell with a pore size of $0.4 \mu \mathrm{m}$ while an equal proportion of BMMSCs were seeded in the upper chamber. After $48 \mathrm{~h}$ of co-cultivation, the expression levels of P53, P21, and TCAB1 in the A549 cells were determined by RT-PCR.

The apoptotic rate of A549 cells was determined by flow cytometry according to the Annexin $\mathrm{V}$ Alexa Fluor488/PI manual of 4ABIO. ROS levels and cell cycle progression were compared between the model and treatment groups using the Reactive Oxygen Species Assay Kit. Immunohistochemistry was performed to detect proSPC as markers of type II alveolar epithelial cells. Three fields, each containing 200 cells, were randomly selected after staining and used to calculate the percentage of type II alveolar epithelial cells to the total number of cells.

\section{Analysis of the effect of BMMSC treatment on ROS, inflammatory factors, and VEGF in elderly macaques}

Serum was isolated from the peripheral blood of macaque obtained at $0,30,60$, and 90 days after BMMSC treatment. Inflammatory factor (IL-1 $\beta$, IL-17A, and TNF- $\alpha$ ) levels in the peripheral blood were detected by ELISA.

After BMMSC treatment, ROS staining was done on the left lung tissue. Sections were then subjected to the same laser intensity at equal exposure times to obtain images. To obtain the $\mathrm{H}$-scores, the Densito Quant in the Quant Center was used to set dark red, brown red, light red, and blue nuclei as strong positive, moderate positive, weak positive, and negative respectively. The protein levels of proinflammatory factors (IL-6, TNF- $\alpha$, IL-1 $\beta$ ) and anti-inflammatory factor (IL-10) in the lung tissues were detected by Western blot. VEGF expression levels in the lung tissues after BMMSC treatment was determined by Western blot. ImageJ was used to analyze the gray values of all western blot images, and to compare the gray values of the internal control band to the gray values of the target protein band. The effects of BMMSCs on peripheral blood Treg cell and FOXP3 ratios in lung tissues of elderly macaques were also determined.

Lymphocytes were isolated from blood samples obtained from the animals at 0, 30, 60, and 90 days after BMMSC treatment. Changes in Treg cell ratios in peripheral blood were detected by flow cytometry. Treg cells were labeled with FOXP3 and changes in FOXP3 content assayed by immunohistochemistry.

\section{Statistical analysis}

Statistical analyses were performed using the SPSS 21.0 statistical software. Data is expressed as mean \pm standard deviation. Statistical differences in the means of three or more than three groups were analyzed by one-way ANOVA (One-Way ANOVA).

\section{Results}

Lung tissue structures and appearance among young and elderly macaques

Elderly macaques were found to have a dull coat that turned white, especially around the head and face. Furthermore, their skin was loose and dry while their faces appeared red (Fig. 1a).

Lung tissues of the young control group and the elderly model group were soft, butterfly-shaped, flexible, and pale red. However, lung sizes of the elderly macaque models were larger visually compared to those of the 


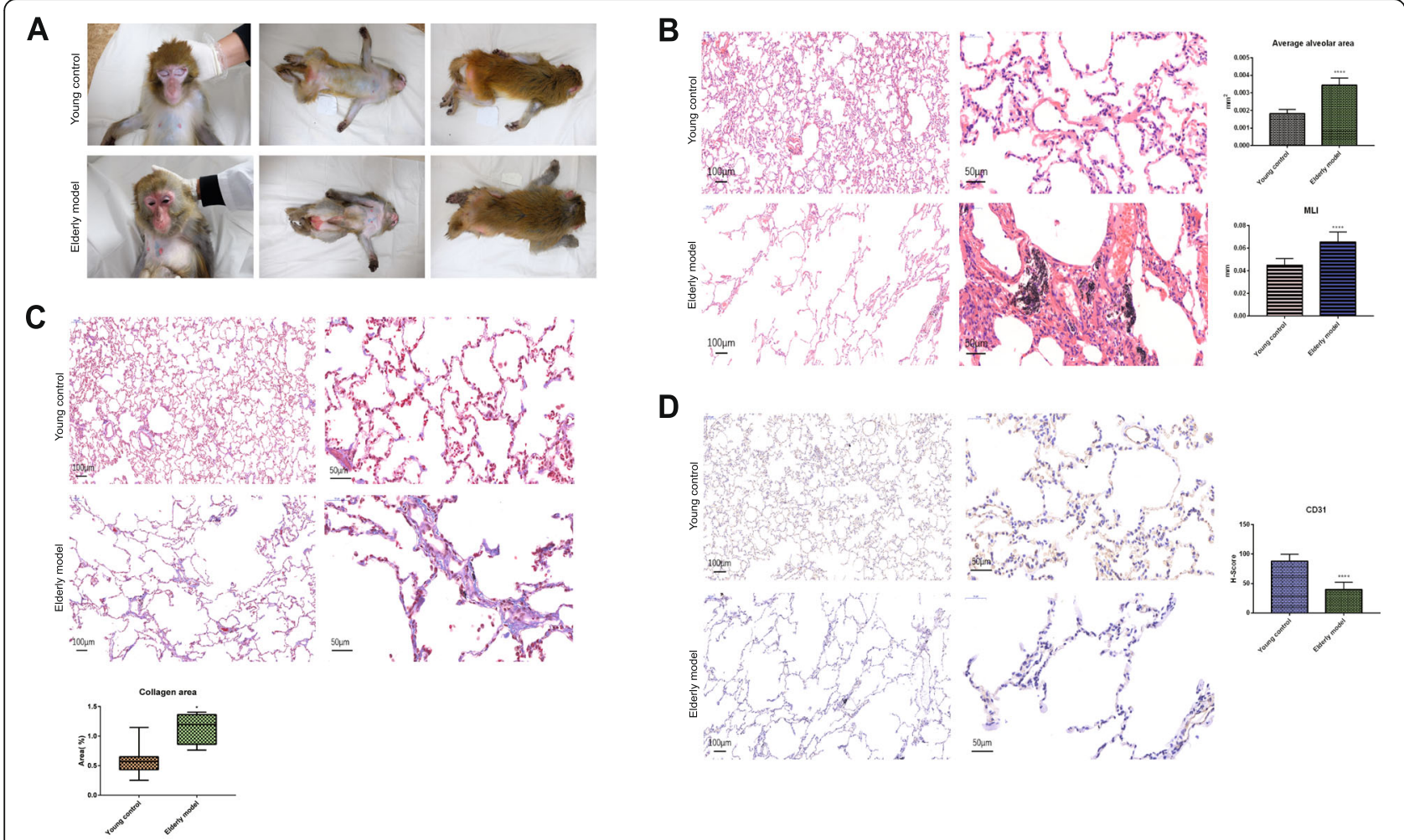

Fig. 1 Differences in appearance and lung tissue structure between the young and elderly macaques. a Age-related changes in appearance between the young control group and the elderly model group. $\mathbf{b}$ Comparison of the lung tissue structure between the young control group and the elderly model group ( $n=5, n$ is for the number of animals analyzed. ${ }^{* * * *} P<0.0001$ when compared with the young control group). c Comparison of the rate of collagen area between the young control group and the elderly model group $\left(n=5, n\right.$ is for the number of animals analyzed. ${ }^{*} P<0.05$ when compared with the young control group). $\mathbf{d}$ Comparison of CD31 expression quantity around the alveoli between the young control group and the elderly model group ( $n=5, n$ is for the number of animals analyzed. ${ }^{* * *} P<0.0001$ when compared with the young control group)

young control models (data shown in supplementary files 2). The young control group exhibited clear lung structures, thin and smooth alveolar walls, no thickening of the alveolar space, no exudates, and small amounts of inflammatory cellular infiltrate around the blood vessels. In the elderly model group, the alveolar wall thickness was uniform, the alveoli were clean and without exudates, and the alveolar cavity was irregularly enlarged and formed the pulmonary bullae. Furthermore, they exhibited a visible pigmentation. When compared to the young group, the elderly model group showed severe inflammation while the average area and MLI were also significantly increased in the elderly model group (Fig. $1 \mathrm{~b} ; p<0.0001)$. Masson's Trichrome stain colored the collagen fibers blue. Compared to the young control group, the collagen area in the lungs of the elderly model group was significantly increased (Fig. 1c; $p<$ 0.05). Immunohistochemical labeling of the vascular endothelial cells with CD31 revealed that the nucleus of lung tissue cells were stained blue while the surface markers of vascular endothelial cells were stained brown. In the elderly group, CD31 expression in the lungs was significantly low when compared to the young control group (Fig. 1d; $p<0.0001$ ).

\section{Cultivation and identification of BMMSCs}

A few fusiform adherent cells were observed under an inverted phase-contrast microscope after 3-4days of BMMSC culturing. The cell fusion rate was $80 \%$ after 9 days of culture. BMMSCs of passages 3 to 5 exhibited a uniform morphology and were dense, spiral, and isolated (Fig. 2a). To confirm the purity of the cultured cells, the $\mathrm{P} 4$ generation immunophenotypes of juvenile macaque BMMSCs were analyzed by flow cytometry. A panel of surface antigens was analyzed. The results showed that BMMSCs were positive for CD29, CD45, CD73, CD90, and $\mathrm{CD} 184$ at percentage rates of $96.35 \pm 0.62,0.16 \pm$ $0.12,95.22 \pm 0.37,96.25 \pm 1.71$, and $93.53 \pm 2.76$, respectively (Fig. 2b; Table 1).

The proliferation assay showed that BMMSCs exhibited an "S" shape, were latent for the first 1-2 days, and entered a logarithmic proliferation phase in which they grew vigorously between days 3 and 7 . On the 8 th day, they entered a plateau phase that was characterized by a reduction in proliferation (Fig. 2c). The P4 generation of 
A
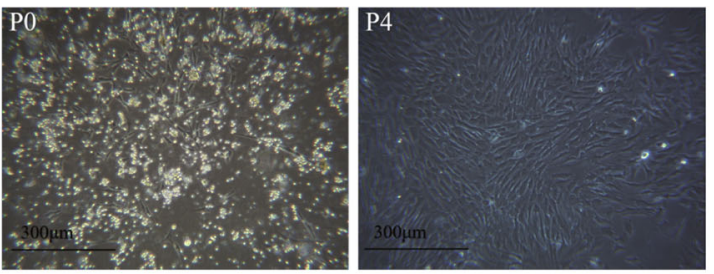

C

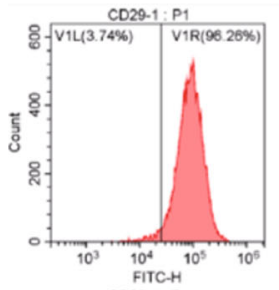

CD90-1: $P$ 1
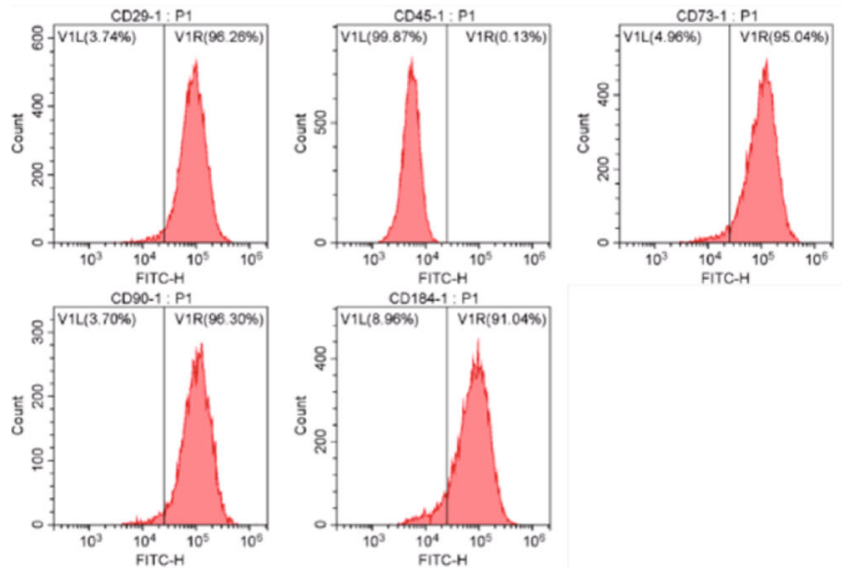

Fig. 2 Cultivation and identification of BMMSCs. a BMMSCs form. b Flow cytometry analyses of BMMSCs. c Proliferation curve of BMMSCs. d Differentiation of BMMSCS

young macaque BMMSCs was used to determine the in vitro differentiation and proliferative capacities. The duration of the differentiation experiment was 14 to 21 days. Cells were cultured in an osteogenic induction medium and allowed to aggregate, form nodules, and accumulate calcium deposits. Alizarin red stain was used to detect precipitated calcium deposits that were an indication of differentiation. Intracellular lipid droplets were stained with oil red O. Red-stained lipid droplets were found in the cells. Proteoglycans were stained with Alcian blue and appeared as smears (Fig. 2d).

\section{Changes in lung tissue structure after BMMSC treatment} Lung textures before treatment were grid-like, groundglass opacity, honeycomb-shaped, with the peripheral, subpleural, and lower lung lobes as the main features. Emphysema was obvious. Before treatment, the average

Table 1 Flow cytometry analysis of surface antigens

\begin{tabular}{lll}
\hline Surface antigen & $\boldsymbol{N}$ & Cell positive rate \\
\hline CD29 & 3 & $96.35 \pm 0.62$ \\
CD45 & 3 & $00.16 \pm 0.12$ \\
CD73 & 3 & $95.22 \pm 0.37$ \\
CD90 & 3 & $96.25 \pm 1.71$ \\
CD184 & 3 & $93.53 \pm 2.76$ \\
\hline
\end{tabular}

$N$ is the number of experimental replicates
B

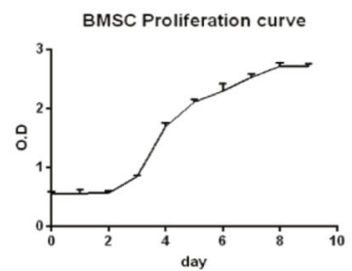

D

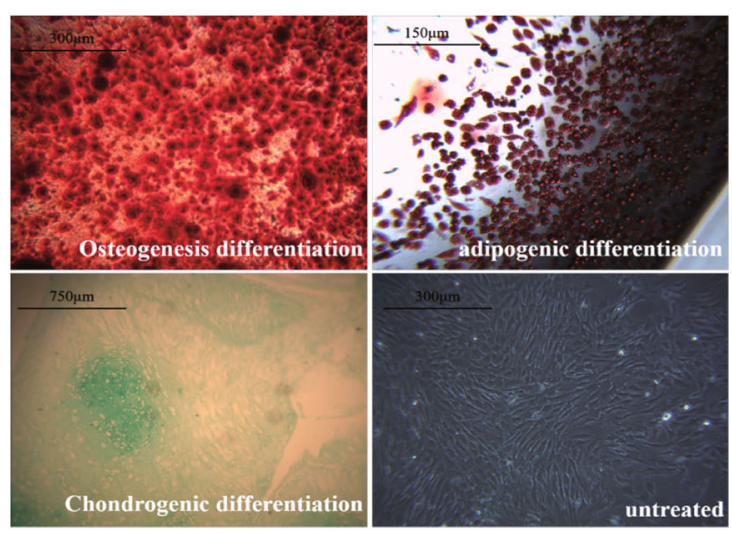

Hounsfield unit was significantly decreased when compared to the control group $(p<0.01)$. In addition, HRCT exhibited an irregular thickening of the leaflet intervals before treatment. After treatment, the small blood vessels in the leaflet were pronounced. This was attributed to the thickening of the wall in the treatment group. PET showed that the ${ }^{18}$ F-FDG uptake that was quantified as the glucose uptake in the lungs decreased after treatment. At 90 and 180 days post-treatment, lung textures were clear with normal hilar. The Hounsfield unit was higher than before treatment. The average Hounsfield units were $-685 \pm 12.53$ and $-705 \pm 18.53$, respectively (Table 2; Fig. 3a).

After 180 days of treatment, lung tissues appeared dark white and red without embolism. However, there were no significant changes between the treatment and the model groups (data shown in supplementary file 3). Although the inflammatory score was not statistically different, the treatment group exhibited low inflammatory levels than the model group. The average alveolar area and alveolar lining interval (MLI) of the model group and treatment groups were significantly increased when compared to the control group $(p<0.05)$. However, the differences in the average alveolar area and alveolar lining interval between the model group and the treatment group were not significantly different (Fig. 3b; $p>0.05$ ). Masson's Trichrome stain showed blue collagen. The 
Table 2 PET-CT changes in elderly macaque lungs after BMMSC treatment

\begin{tabular}{lccl}
\hline & $\boldsymbol{n}$ & Hounsfield Unit & SUV max \\
\hline Control & 5 & $-672 \pm 12.5$ & $0.4 \pm 0.09$ \\
Prior treatment & 5 & $-853 \pm 25.3^{\$}$ & $0.7 \pm 0.06^{\$}$ \\
90 days after treatment & 5 & $-685 \pm 12.53^{*}$ & $0.5 \pm 0.08^{*}$ \\
180 days after treatment & 5 & $-705 \pm 18.53^{*}$ & $0.3 \pm 0.07^{* *}$ \\
\hline
\end{tabular}

$n$ is for the number of animals analyzed, ${ }^{\$} p<0.05$ when compared to the control group, ${ }^{*} p<0.05$ when compared with prior

collagen area of the treatment group was significantly reduced $(p<0.05)$ when compared to the model group (Fig. 3c). To determine changes in capillary density around the alveoli after cell transplantation, immunohistochemistry was performed using CD31 as a marker of vascular endothelial cells. The nucleus were stained blue while the capillaries with CD31 surface markers were stained brown. Compared to the model group, the CD31 content around the alveoli was significantly increased in the treatment group (Fig. 3d; $p<0.0001$ ).

Effect of BMMSCs on senile type 2 alveolar epithelial cells Type II alveolar epithelium plays a significant role in lung tissue aging. Among the elderly, the quantity and quality of type II alveolar epithelial cells are significantly reduced [14]. In this study, the effect of BMMSCs on lung structure was determined using type II alveolar epithelial cells. Hydrogen peroxide was used to establish an aging model of A549 cells. Different hydrogen peroxide concentrations were found to induce different degrees of aging in A549 cells. At $600 \mu \mathrm{mol} / \mathrm{L}$ hydrogen peroxide concentration, the A549 cells exhibited senescence after $6 \mathrm{~h}$ of induction (data shown in supplementary file 4). This concentration was established to be the best for inducing A549 cell senescence. After the indirect coculture of aging A549 cell model with BMMSCs for 48 $\mathrm{h}$, the lower layer of A549 cells was used to determine the effects of BMMSCs on the aging A549 cell model. The expression levels of P53 and P21 were found to be significantly decreased $(p<0.001, p<0.01)$ in the treatment group compared to the model group. However, the expression levels of TCAB1 increased significantly $(p<$ 0.05; Fig. 4a). After indirect co-culture, the ROS level, apoptosis ratio, and A549 cell cycles were detected by flow cytometry. Compared to the model group, the ROS level and apoptosis ratio in the treatment group were found to be significantly reduced $(p<0.0001, p<0.001$, respectively) (Fig. $4 \mathrm{~b}, \mathrm{c}$ ). In the treatment group, proliferation was accelerated in the G2 phase (Fig. $4 \mathrm{~d} ; p<$ 0.01). To verify the in vitro effects of BMMSCs on aging A549 cell model, proSPC was used as an in vivo marker for type II alveolar epithelial cells. It was found that type II alveolar epithelial cells were either round or oval and scattered in the alveolar wall. The number of type II alveolar epithelial cells in the model group was significantly low when compared to the control group $(p<$ 0.001). However, in the treatment group, type II alveolar epithelial cells were significantly elevated when compared to the model group (Fig. 4e; $p<0.01$ ).

\section{VEGF and TGF- $\beta 1$ expression levels in lung tissues}

There were changes in the density of capillaries around the alveoli that necessitated the determination of VEGF levels in the lungs. Compared to the control group, VEGF levels in the model group were significantly low $(p<0.05)$. After BMMSC treatment, VEGF levels in the treatment group were significantly elevated when compared to the model group (Fig. 5a; $p<0.05$ ). Since the collagen area in the lung tissue was changed after the cells had been transferred, TGF- $\beta 1$ levels in the lung tissue were determined. The expression levels of TGF- $\beta 1$ in the lung tissues were found to significantly increase with age. However, there were no significant changes after BMMSC treatment (Fig. 5b).

\section{ROS and inflammatory factor levels after BMMSC treatment}

Studies have revealed that the nine aging hallmarks are stem cell failure, intercellular communication changes, genomic instability and telomere wear, epigenetic changes, loss of protein homeostasis, nutrition changes, mitochondrial dysfunctions, and cellular senescence [15]. The main causes and impacts of these events have not been established. However, studies have documented that the causes and commonalities of these events are associated with the immune system. Inflammatory aging is characterized by elevated levels of immune cell infiltration as well as elevated levels of pro-inflammatory cytokines and chemokines in the tissue microenvironment and circulatory system [15]. Under normal physiological conditions, ROS in the cells is constantly generated and eliminated. Therefore, maintaining appropriate cellular ROS levels is important for the stability of cell functions. During aging, ROS levels may also be elevated due to mitochondrial stress, damage, and persistent inflammation [16]. Elevated ROS levels enhance cellular damage and stimulates the immune cells to produce more proinflammatory factors [17]. The immune regulatory and damage repair functions of mesenchymal stem cells are critical. Studies have reported that MSCs control inflammation and ROS production through paracrine and mitochondrial transfer between MSCs and aging cells $[18,19]$. In this study, it is shown that mesenchymal stem cells influenced lung tissue degeneration by altering inflammation and ROS levels in elderly macaques. Frozen lung tissue sections were used to detect ROS levels. An inverted fluorescent microscope showed that the nucleus of lung cells were stained blue while the 


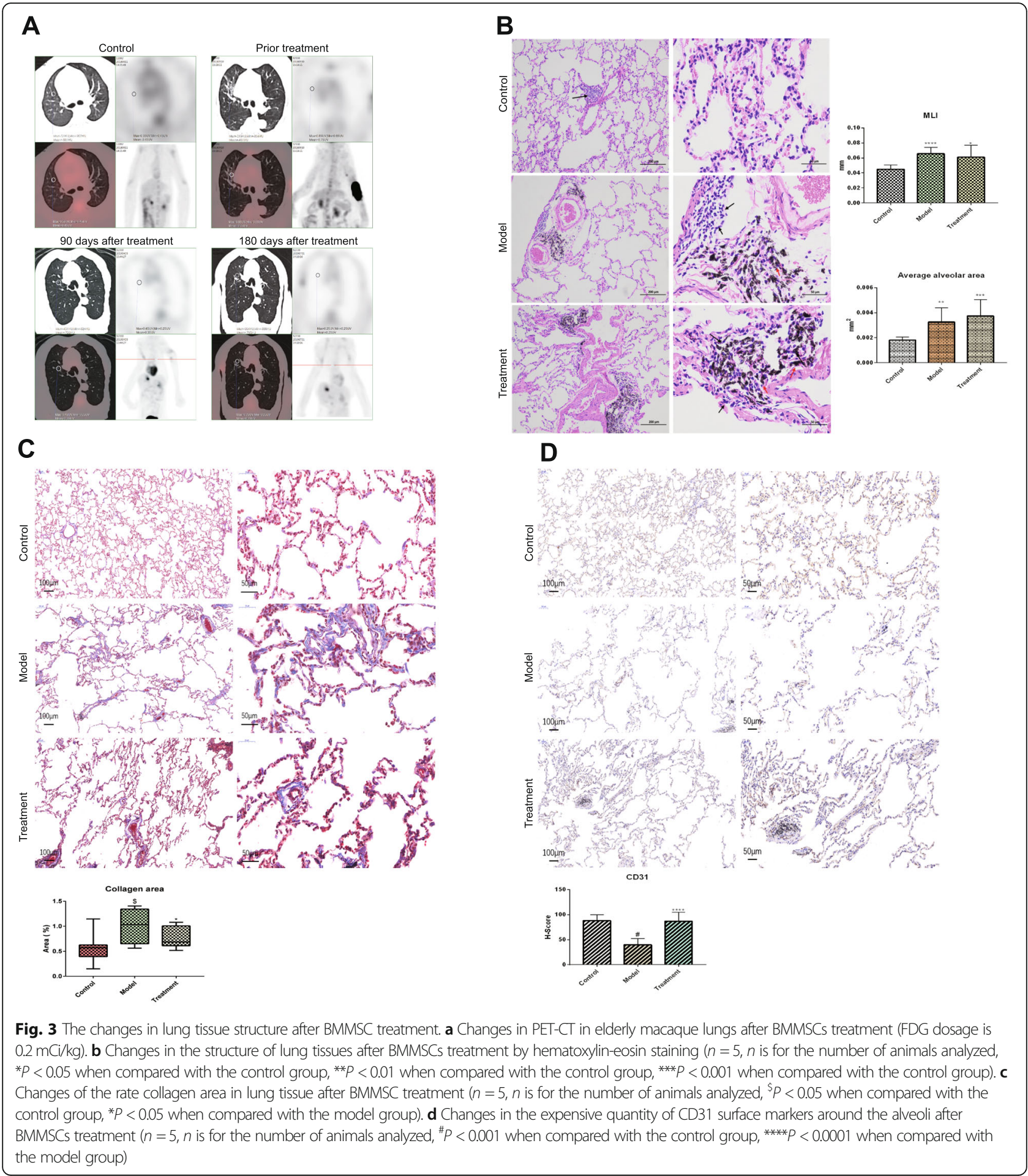

cytoplasm exhibited a red fluorescence. Compared to the model group, ROS levels in the treatment group were significantly low (Fig. 6a; $p<0.01$ ). To elucidate on the regulatory effects of BMMSCs on aging-associated inflammation, IL-1 $\beta$, IL-17A, and TNF- $\alpha$ levels were detected by ELISA. Compared to the model group, IL-1 $\beta$ levels were found to be significantly low in blood serum $(p<0.05)$ at 30 and 60 days after BMMSC treatment. After 90 days of treatment, these levels had reverted to normal. Moreover, TNF- $\alpha$ levels were found to be significantly low after 30 days $(p<0.05)$. However, they reverted to their normal levels after 60 days and remained unchanged. There were no significant variations in IL-17A levels (Fig. 6b). Alterations in 


\section{A}
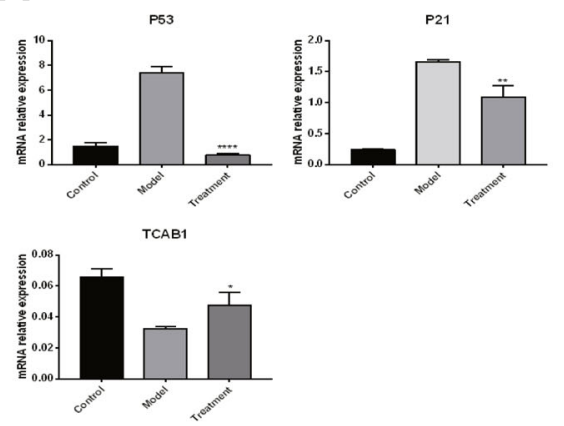

B
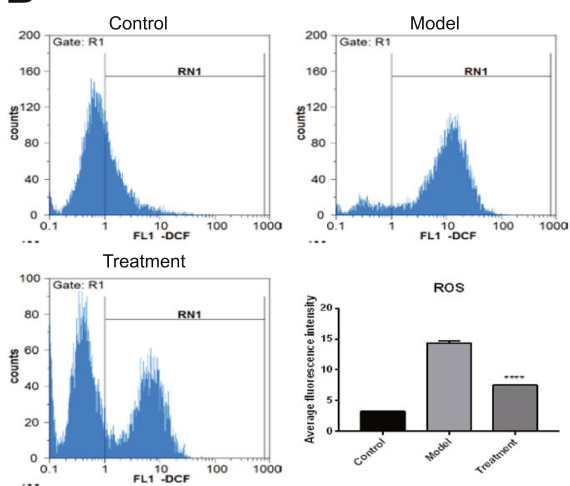

C
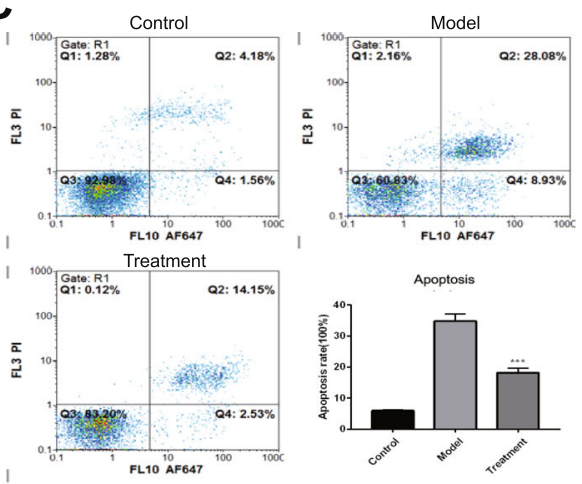

E
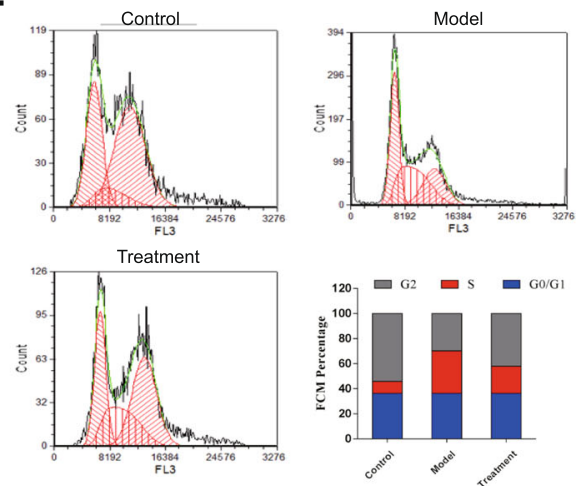

\section{$\mathbf{F}$}
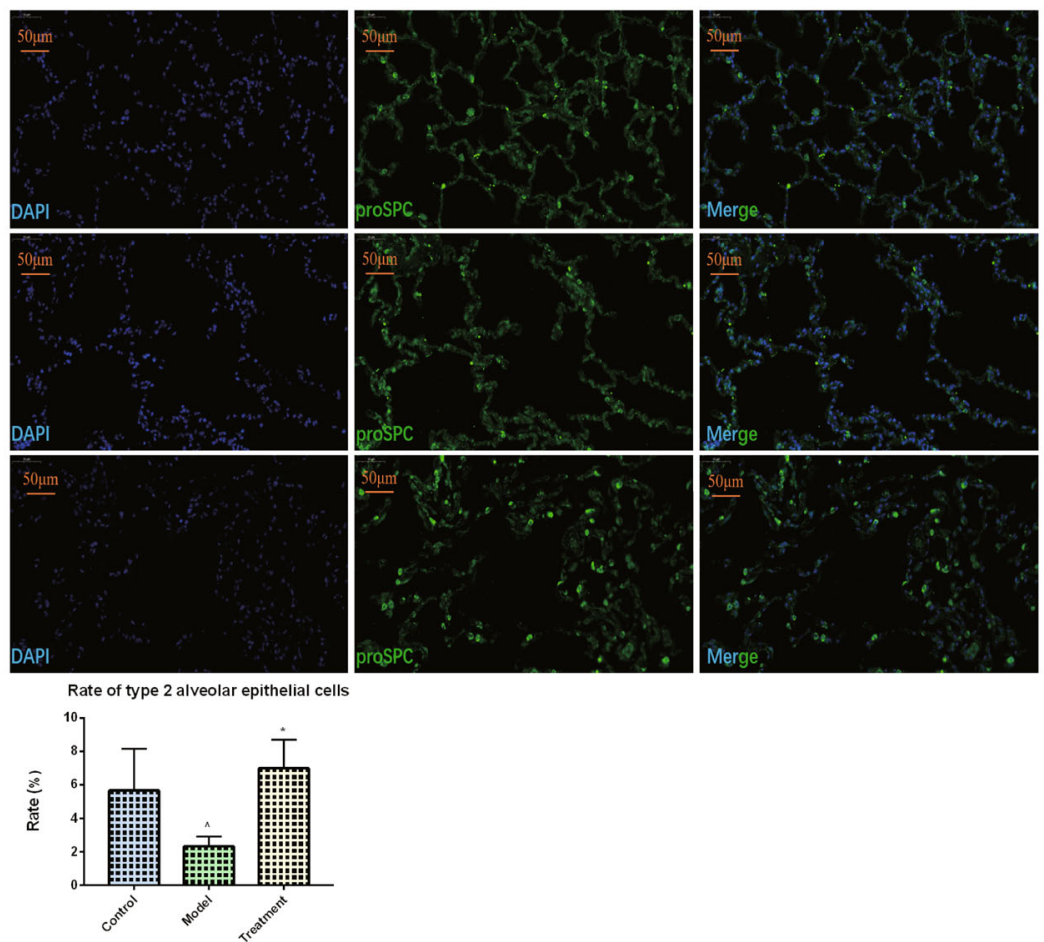

Fig. 4 (See legend on next page.) 
(See figure on previous page.)

Fig. 4 Effects of BMMSCs on senile type 2 alveolar epithelial cells. a qPCR detection of aging-related gene expression after co-culture in vitro $\left(n=3, n\right.$ is the number of repeated experiments, ${ }^{*} P<0.05$ when compared with the model group, ${ }^{* *} P<0.01$ when compared with the model group, ${ }^{* * * *} P<0.0001$ when compared with the model group). $\mathbf{b}$ Changes in ROS level of type 2 alveolar epithelial cells after co-culture in vitro ( $n=3, n$ is the number of repeated experiments, ${ }^{* *} P<0.001$ when compared with the model group, ${ }^{* * * *} P<0.0001$ when compared with the model group). c The apoptosis rate changes of type 2 alveolar epithelial cells after co-culture in vitro $(n=3, n$ is the number of repeated experiments, ${ }^{* *} P<0.001$ compared with the model group, ${ }^{* * *} P<0.0001$ compared with the model group). $\mathbf{d}$ Proliferation changes of senile type 2 alveolar epithelial cells after co-culture in vitro ( $n=3, n$ is the number of repeated experiments). e Effect of BMMSCs on the number of type II alveolar epithelial cells in the lung tissue $\left(n=5, n\right.$ is for the number of animals analyzed, ${ }^{* *} P<0.01$ when compared with the model group, $\wedge P<0.001$ compared with the control group)

inflammatory factor (IL-1 $\beta$, IL-6, TNF- $\alpha$, and IL-10) levels in the lungs after BMMSC treatment were determined by western blot. The levels of IL-1 $\beta$, IL- 6 , and TNF- $\alpha$ in the treatment group were significantly low when compared to the model group while IL-10 levels in the model group were significantly low than in the control group $(p<0.05)$, but were significantly elevated after BMMSC treatment (Fig. 6c; $p<0.05$ ).

\section{Effect of BMMSC treatment on immune regulatory cells}

As described above, there were changes in the expression levels of inflammatory factors in peripheral blood and lung tissues after BMMSC treatment. Treg cells have immune-regulatory functions and play a vital role in the regulation of inflammation. Treg cell ratios in the peripheral blood were measured by flow cytometry. Compared to the normal group, it was revealed that Treg ratios in macaque peripheral blood decreased significantly at 30 days after BMMSC treatment $(p<0.01)$, and reached their minimum levels at 60 days after treatment $(p<0.0001)$. Treg cell ratio changes at 60 and 90 days were not significant (Fig. $7 \mathrm{a} ; p>0.05$ ). To determine the consistency of Treg cell changes in the periphery and lung tissues, a Treg cell surface marker (FOXP3) was used for immunohistochemical detection. FOXP3 levels of the model group lung tissue were found to be significantly elevated when compared to the control group $(p<0.01)$. In addition, FOXP3 levels in the treatment group were significantly low when compared to the model and control groups $(p<0.0001$; Fig. $7 \mathrm{~b})$.

\section{Discussion}

Age-associated lung tissue structural changes are characterized by enlarged alveoli, damaged alveolar walls, decreased gas exchange surface area, increased airway obstruction or occlusion, decreased pulmonary vascular density, deepened fibrosis, and decreased elastin content [2]. In this study, these phenomena were observed through pathological analysis.

Chemotaxis of mesenchymal stem cells enhances their accumulation in injured sites. These cells secrete cytokines (such as KGF, HGF) and some RNA-rich microvesicles. This paracrine effect delays cell senescence and apoptosis and lung tissue repair and inhibits fibrosis. Mitochondrial transfer and communication between MSCs and neighboring cells are involved in tissue repair [20-22].

In this study, we report on the effects of BMMSCs on lung tissue degeneration. Lung tissue changes were detected by PET-CT. There was a significant increase in $\mathrm{x}$ ray transmittance (Hounsfield unit) in lung tissues after BMMSC treatment. A significant decrease in SUV max values and fibrosis were observed. Compared to the model group, collagen deposition in the treatment group was significantly inhibited while the alveolar vascular density was significantly elevated. However, the reduction in alveolar size was not significant. These results were consistent with
A

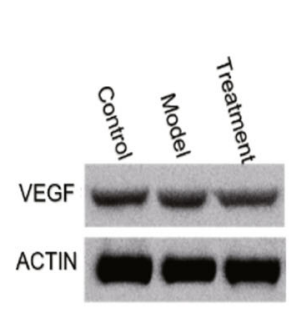

VEGF

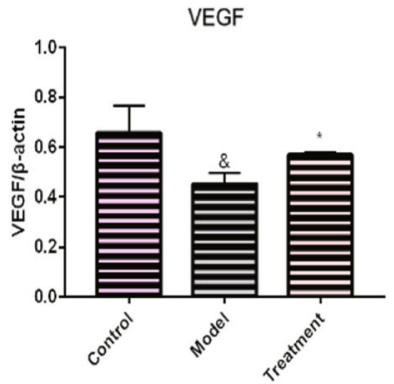

B

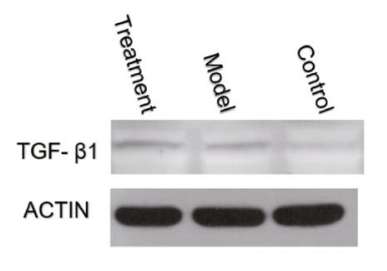

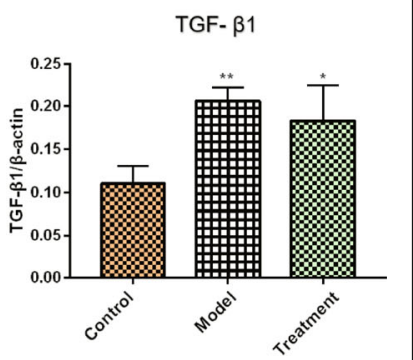

Fig. 5 Changes in VEGF and TGF- $\beta 1$ level in the lung tissue after BMMSCs treatment. a VEGF $\left(n=5, n\right.$ is for the number of animals analyzed, ${ }^{\circledR} P<0.05$ compared with the control group, ${ }^{*} P<0.05$ compared with the model group). $\mathbf{b}$ TGF- $\beta 1$ ( $n=5, n$ is for the number of animals analyzed. ${ }^{*} P<0.05$ compared with the control group, ${ }^{* *} P<0.01$ compared with the control group) 
A

ROS

DAPI
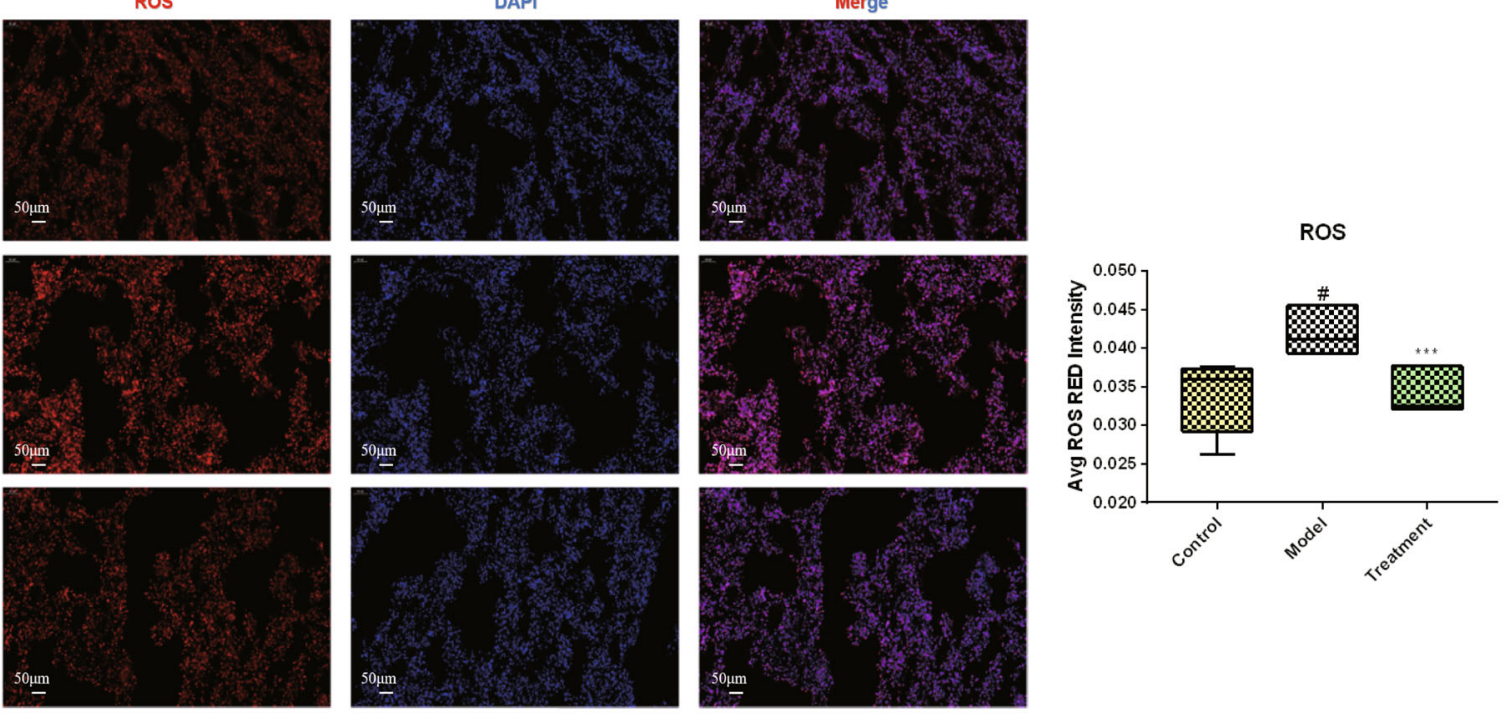

B

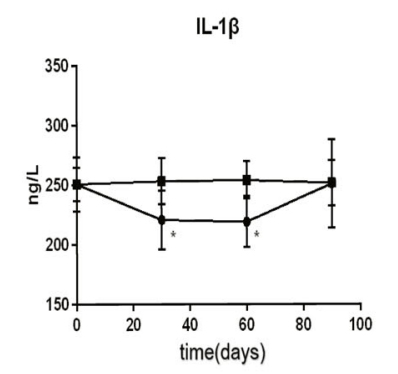

-Treatment

TNF-a

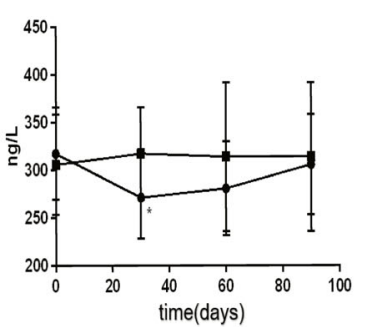

IL-17A

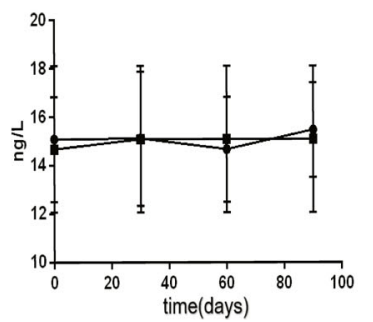

C

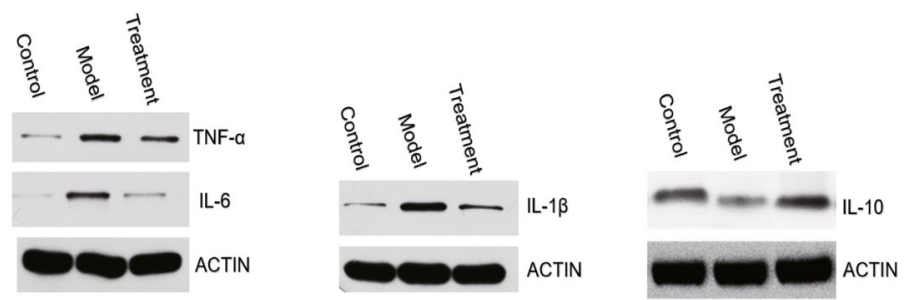

IL-1 $\beta$

IL-10
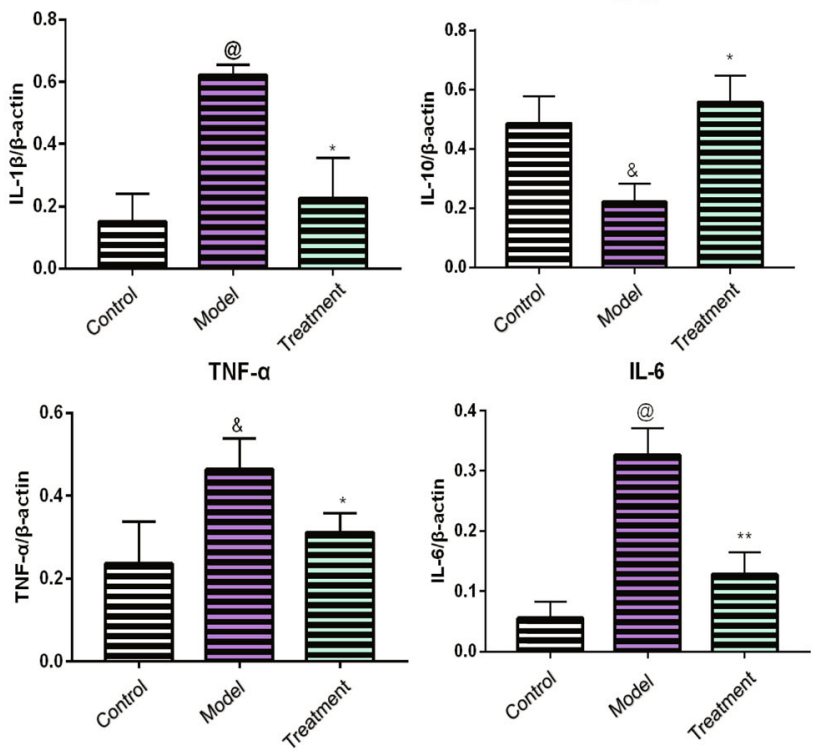

Fig. 6 (See legend on next page.) 
(See figure on previous page.)

Fig. 6 Changes in the level of ROS and inflammatory factors after BMMSCS treatment. a Changes in ROS level after BMMSCS treatment $(n=5, n$ is for the number of animals analyzed, ${ }^{\#} P<0.001$ compared with the control group, ${ }^{* * *} P<0.001$ compared with the model group). $\mathbf{b}$ Changes in the level of inflammatory factors in peripheral blood after BMMSCs treatment $(n=5, n$ is for the number of animals analyzed $* P<0.05$ compared with the model). $\mathbf{c}$ Changes in inflammatory factors in lung tissue after BMMSCs treatment $\left(n=5, n\right.$ is for the number of animals analyzed, ${ }^{*} P<0.05$ compared with the model group, ${ }^{* *} P<0.01$ compared with the model group, ${ }^{\circledR} p<0.05$ compared with the control group, ${ }^{\circledR} p<0.001$ compared with the control group)

those reported by previous studies on mesenchymal stem cells in the treatment of COPD [23-25]. Breathing is a dynamic process. Changes in the tissues around the alveoli determine the lung's inspiratory function and alveolar sizes. Due to air volume variations in the lungs during inspiration and expiration, PET-CT or hematoxylin-eosin staining may not sufficiently evaluate whether BMMSCs can repair alveolar size deterioration during actual respiration in elderly lung tissues. Therefore, assessment of the beneficial effects of BMMSCs should be performed from multiple focal points.

SA- $\beta$-gal is a hydrolase enzyme that catalyzes the hydrolysis of $\beta$-galactosides into monosaccharides in senescent cells. P53 and its downstream genes (P21 and TCAB1) control cellular aging $[15,26]$.

We confirmed that BMMSCs reversed age-associated type II alveolar epithelial cell (A549 cells) characteristics. These results were consistent with those reported in a previous study of the effects of bone marrow mesenchymal stem cells on 293T cell senescence models [26].

High inflammation and oxidative stress enhance tissue and organ degeneration during aging [7, 15, 27]. In this study, we found high age-associated inflammatory and oxidative stress levels in elderly macaques. The inconsistency between the circulatory and lung tissue expression levels of various inflammatory factors differed from those previously reported in rodent lung injury models $[28,29]$. The fact that IL-6 was downregulated in the lung tissues after BMMSC treatment shows that mesenchymal stem cells, such as BMMSCs, have a regenerative effect on lung tissue aging processes.

Treg cells regulate immune responses. Specifically, they play a central role in immune homeostasis and in preventing autoimmunity. They are secreted by the thymus and lymph and transported through the entire body. They inhibit the activation and proliferation of potential self-reactive $\mathrm{T}$ cells, thereby regulating the body's immunity and inflammation. Studies have documented that the number and functions of Treg cells change significantly in the aging body. Zhao et al. reported that the ratio of Treg cells in the CD4+ cells was significantly elevated and their function was significantly inhibited in the peripheral blood of elderly mice [30]. IL-10 is a multi-functional cytokine that regulates cell growth and differentiation, participates in inflammatory reactions and immune responses, and is recognized as an immunomodulatory cytokine for all innate immune cells [31].
Studies have documented that the number and function of Treg cells have a regulatory effect on the IL-10 secretory roles of $\mathrm{CD} 4+$ and $\mathrm{CD} 25+$. Aging affects the capacity of CD4 (+), CD25 (+), and FOXP3FOXP3 (+) T cells to regulate IL-10 production [32]. Mesenchymal stem cells are powerful immune regulatory cells that exhibit their effects on Treg cells and IL-10 production. Studies have reported that mesenchymal stem cells enhance the production of IL-10 by communicating with macrophages, B lymphocytes, and dendritic cells or by secreting PGE2, ID0, IL-6, and HO-1 [33]. Treg cell levels obtained in this study were inconsistent with those reported in previous studies on the regulation of Treg cells by mesenchymal stem cells under extremely high inflammatory conditions [33]. However, it was not established whether BMMSCs enhanced Treg cell tissue entry, thereby inhibiting Treg ratios in the peripheral blood. FOXP3 was, therefore, used as a marker to determine Treg cell levels in lung tissues. Lung tissue findings regarding FOXP3 levels were consistent with those of the peripheral blood. However, FOXP3 levels in the lung tissues of treatment group were significantly reduced. Studies evaluating the role of MSCs in immune regulation in healthy individuals have not been documented while their effects have only been demonstrated in cellbased therapy and disease scenarios.

Interleukin 10 levels obtained in this study were consistent with those reported in a previous mesenchymal stem cell treatment model of lung injury [34]. Decreased Treg cell ratios were inconsistent with the phenomenon of elevated IL-10. This implied that BMMSCs enhanced IL-10 secretion through other mechanisms other than Treg.

In summary, BMMSCs inhibit aging-associated lung degeneration. The limitations of this study were that the impact of BMMSCs on lung functions and the mechanisms by which BMMSCs improved lung degeneration were not determined.

\section{Conclusions}

i. The elderly pulmonary degenerative macaque models revealed that the alveolar cavity was enlarged, lung structure was disordered, there was increased pigmentation, and the degree of fibrosis was elevated while the capillary density was decreased. 
A

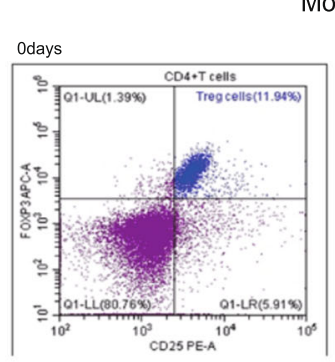

Model
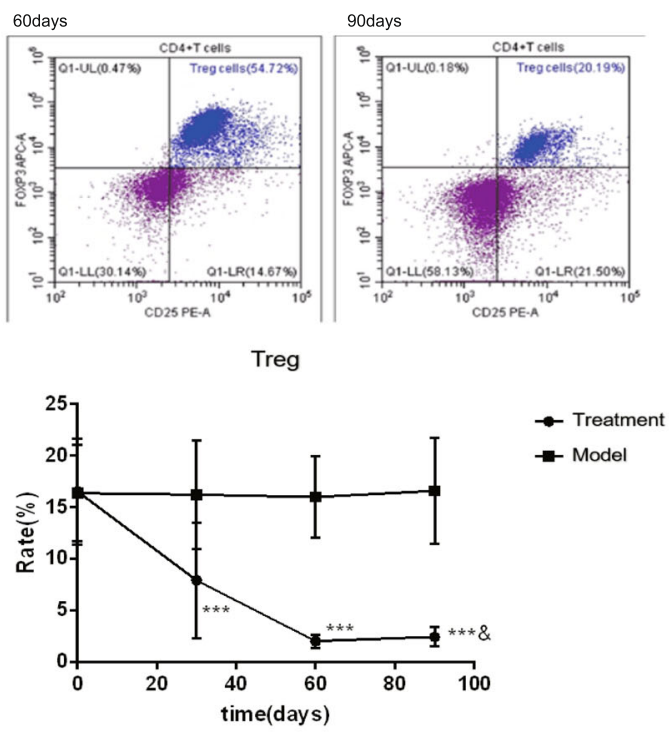

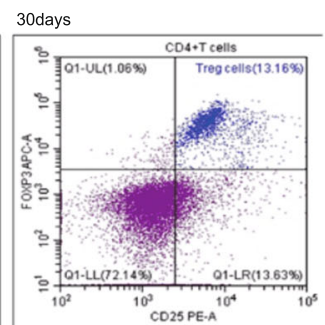

Treatment
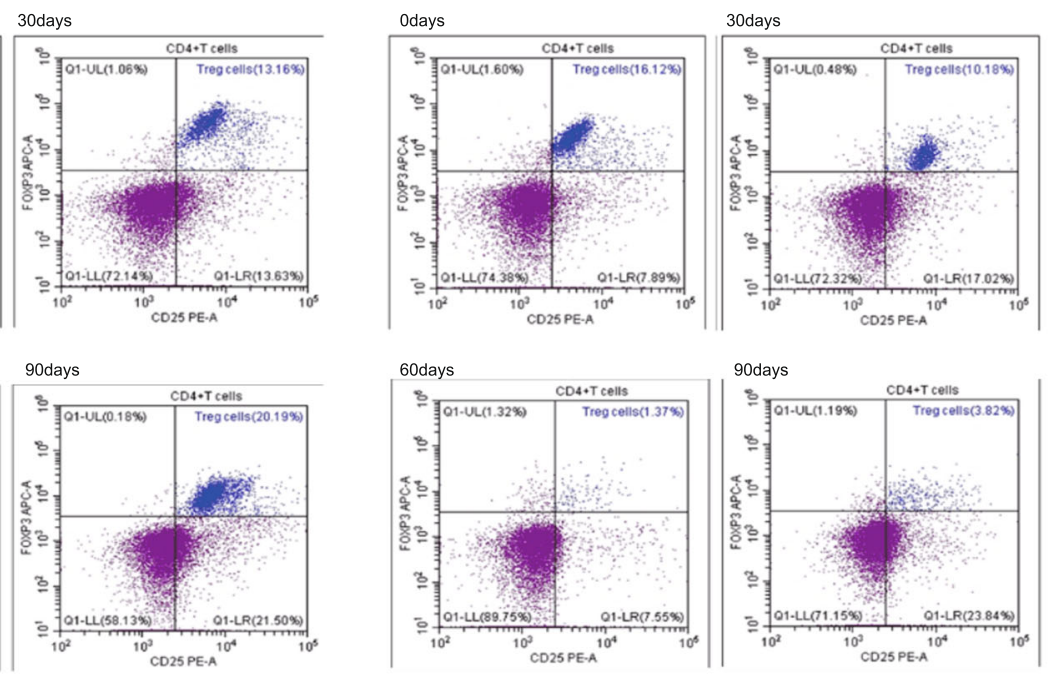

\section{B}
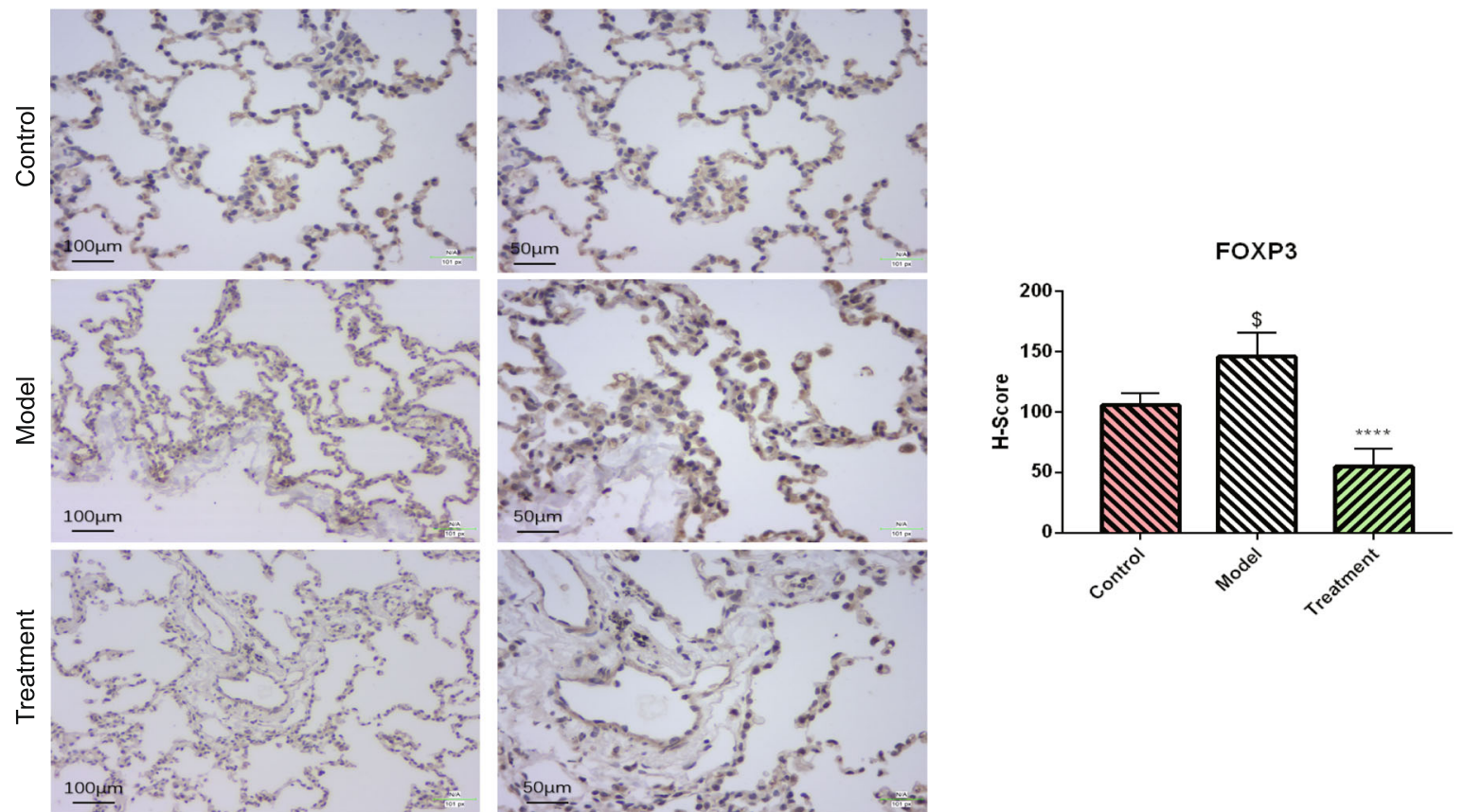

Fig. 7 (See legend on next page.) 
(See figure on previous page.)

Fig. 7 Effect of BMMSC treatment on immune regulatory cells. a Changes of Treg cell ratio in peripheral blood after BMMSC treatment (FOXP4 antibody, CD25 antibody, and CD4 antibody were used to co-label Treg cells, $n=5, n$ is for the number of animals analyzed. ${ }^{* * *} P<0.001$ compared with the model group, ${ }^{\circledR} P>0.05$ compared with 60 days after treatment). $\mathbf{b}$ Changes of FOXP4 content in the lung tissue after BMMSC treatment $\left(n=5, n\right.$ is for the number of animals analyzed. ${ }^{* * *} P<0.0001$ compared with the model group, ${ }^{\$ *} P<0.001$ compared with the control group)

ii. BMMSCs inhibited the degree of pulmonary fibrosis in elderly macaques, suppressed lung and peripheral blood inflammatory levels, enhanced VEGF expression in lung tissues, increased capillary density around the alveoli, and suppressed Treg cell levels in peripheral blood and lung tissues.

iii. BMMSCs suppressed the expression of type II alveolar epithelial aging-related genes, inhibited its apoptosis and oxidative stress levels, and enhanced its proliferation. BMMSCs also elevated the number of type II alveolar epithelium in lung tissues.

\section{Supplementary Information}

The online version contains supplementary material available at https://doi. org/10.1186/s13287-021-02201-3.

Additional file 1. Preparation and identification of bone marrow mesenchymal stem cells of macaque

Additional file 2. Comparison of lung size between the young control group and the elderly model group

Additional file 3. No significant changes between the treatment and the model groups

Additional file 4. Hydrogen peroxide-induced senescence of A549 cells and $\beta$-galactosidase staining $(100 \times)$

\section{Abbreviations}

BMMSCs: Bone marrow mesenchymal stem cells; FOXP3: Recombinant Forkhead Box P3; IL: Interleukin; P53: Tumor Protein 53; P21: Tumor Protein 21; TERT: Telomerase reverse transcriptase; MSCs: Mesenchymal stem cells; CCK-8: Cell counting kit-8; ${ }^{18}$ F-FDG: $\beta$-2-[18 F]-Fluoro-2-deoxy-D-glucose; FBS: Fetal bovine serum; COPD: Chronic obstructive pulmonary disease

\section{Acknowledgements}

We thank Freescience's Experts for assisting with the preparation of this manuscript.

\section{Authors' contributions}

YKY, YL, XQZ, and XHP designed the study. YKY, XQZ, YL, QW, GPR,YYW, CT, $F D, G H Z, H Y H$, and MW carried out the experiments. YKY, YL, and YYW analyzed the data. YKY, YL GPR, and XHP drafted and revised the paper. All authors read and approved the final manuscript for publication.

\section{Funding}

This work was supported by grants from the Yunnan Science and Technology Plan Project Major Science and Technology Project (2018ZF007) and the Yunnan Fundamental Research Projects (2017FB042).

\section{Availability of data and materials}

All data generated or analyzed during this study are included in this published article.

\section{Ethics approval and consent to participate}

Experimental protocols were approved by the Experimental Animal Ethics Committee of the 920th Hospital of the PLA Joint Logistics Support Force. The approval number: SYXK (AMY)2017-0051
Consent for publication

Not applicable.

\section{Competing interests}

The authors declare that they have no competing interests.

\section{Author details}

${ }^{1}$ Kunming Key Laboratory of Stem Cell and Regenerative Medicine, 920th Hospital of the PLA Joint Logistics Support Force, Kunming 650032, Yunnan Province, China. ${ }^{2}$ Stem Cells and Immune Cells Biomedical Techniques Integrated Engineering Laboratory of State and Regions, 920th Hospital of the PLA Joint Logistics Support Force, Kunming 650032, Yunnan Province, China. ${ }^{3}$ Cell Therapy Technology Transfer Medical Key Laboratory of Yunnan Province, Kunming, Yunnan Province, China. ${ }^{4}$ Kunming Medical University, Kunming, Yunnan Province, China. ${ }^{5}$ Department of Nuclear Medicine, the First Affiliated Hospital of Kunming Medical University, Kunming, Yunnan Province, China.

Received: 13 July 2020 Accepted: 31 January 2021

Published online: 01 March 2021

References

1. 2015-2050年中国人口老龄化趋势与老年人口预测 [J]. 中国社会医学杂 志, 2018.

2. Tran D, Rajwani K, Berlin DA. Pulmonary effects of aging. Curr Opin Anesthesiol. 2017;31(1):1.

3. Verbeken EK, Cauberghs M, Mertens I, et al. The senile lung. Comparison with normal and emphysematous lungs. 1. Structural aspects. Chest. 1992; 101(3):793-9.

4. Turner JM, Mead J, Wohl ME. Elasticity of human lungs in relation to age. J Appl Physiol. 1968;25(6):664-71.

5. Lowery EM, Brubaker AL, Kuhlmann E, et al. The aging lung. Clin Interv Aging. 2013;8:1489-96.

6. Skloot GS. The effects of aging on lung structure and function. Clin Geriatr Med. 2017:33(4):447-57.

7. Meiners S, Eickelberg O, Konigshoff M. Hallmarks of the ageing lung. Eur Respir J. 2015:45(3):807-27.

8. Xi J, Yan X, Zhou J, et al. Mesenchymal stem cells in tissue repairing and regeneration: Progress and future. Burns Trauma. 2013;1(1):13-20.

9. Kenneth S, Yerkovich ST, Chambers DC. Mesenchymal stem cells and the lung. Respirology. 2013;18(3):397-411.

10. Cui $P$, Xin H, Yao Y, et al. Human amnion-derived mesenchymal stem cells alleviate lung injury induced by white smoke inhalation in rats. Stem Cell Res Ther. 2018;9(1):101.

11. Rubio GA, Elliot SJ, Wikramanayake TC, et al. Mesenchymal stromal cells prevent bleomycin-induced lung and skin fibrosis in aged mice and restore wound healing. J Cell Physiol. 2018;233(8):5503-12.

12. Sato K, Oiwa R, Kumita W, et al. Generation of a nonhuman primate model of severe combined immunodeficiency using highly efficient genome editing. Cell Stem Cell. 2016;19(1):127-38.

13. Gibbs RA, Rogers J, Katze MG, et al. Evolutionary and biomedical insights from the rhesus macaque genome. Science (New York, NY). 2007;316(5822): 222-34.

14. Barnes PJ. Inflammatory mechanisms in patients with chronic obstructive pulmonary disease. J Allergy Clin Immunol. 2016;138(1):16-27.

15. Lopez-otin C, Blasco MA, Partridge $L$, et al. The hallmarks of aging. Cell. 2013:153(6):1194-217.

16. Rottenberg $\mathrm{H}$, Hoek JB. The path from mitochondrial ROS to aging runs through the mitochondrial permeability transition pore. Aging Cell. 2017; 16(5):943-55. 
17. De la Fuente $M$, Miquel J. An update of the oxidation-inflammation theory of aging: the involvement of the immune system in oxi-inflamm-aging. Curr Pharm Des. 2009;15(26):3003-26.

18. Paliwal $S$, Chaudhuri $R$, Agrawal $A$, et al. Regenerative abilities of mesenchymal stem cells through mitochondrial transfer. J Biomed Sci. 2018;25(1):31.

19. Harrell CR, Sadikot RT, Pascual J, et al. Mesenchymal stem cell-based therapy of inflammatory lung diseases: current understanding and future perspectives. Stem Cells Int. 2019;2019:4236973.

20. Savukinas UB, Enes SR, Sjoland AA, et al. Concise review: the bystander effect: mesenchymal stem cell-mediated lung repair. Stem Cells. 2016;34(6): 1437-44.

21. Lau AN, Goodwin M, Kim CF, et al. Stem cells and regenerative medicine in lung biology and diseases. Mol Ther. 2012;20(6):1116-30.

22. Behnke J, Kremer S, Shahzad T, et al. MSC based therapies-new perspectives for the injured lung. J Clin Med. 2020;9(3). https:/doi.org/10.3390/jcm9030682.

23. Fikry EM, Safar MM, Hasan WA, et al. Bone marrow and adipose-derived mesenchymal stem cells alleviate methotrexate-induced pulmonary fibrosis in rat: comparison with dexamethasone. J Biochem Mol Toxicol. 2015;29(7):321-9.

24. Wecht S, Rojas M. Mesenchymal stem cells in the treatment of chronic lung disease. Respirology.

25. Huang $\mathrm{K}$, Kang $\mathrm{X}$, Wang $\mathrm{X}$, et al. Conversion of bone marrow mesenchymal stem cells into type II alveolar epithelial cells reduces pulmonary fibrosis by decreasing oxidative stress in rats. Mol Med Rep. 2015;11(3):1685-92.

26. Pan $\mathrm{XH}$, Chen $\mathrm{YH}$, Yang YK, et al. Relationship between senescence in macaques and bone marrow mesenchymal stem cells and the molecular mechanism. Aging. 2019;11(2):590-614.

27. Murray MA, Chotirmall SH. The impact of immunosenescence on pulmonary disease. Mediators Inflamm. 2015:1-10. https://doi.org/10.1155/2 015/692546

28. Gupta N, Su X, Popov B, et al. Intrapulmonary delivery of bone marrowderived mesenchymal stem cells improves survival and attenuates endotoxin-induced acute lung injury in mice. J Immunol. 2007;179(3):185563.

29. Mei SHJ, Mccarter SD, Deng Y, et al. Prevention of LPS-induced acute lung injury in mice by mesenchymal stem cells overexpressing angiopoietin 1. PLoS Med. 2007;4(9):e269.

30. Zhao $L$, Sun $L$, Wang $H$, et al. Changes of $C D 4+C D 25+F o x p 3+$ regulatory $T$ cells in aged Balb/c mice. J Leukoc Biol. 2007;81(6):1386-94.

31. Gabryšová L, Howes A, Saraiva M, et al. The regulation of IL-10 expression. Curr Topics Microbiol Immunol. 2014;380:157-90.

32. Hwang KA, Kim H-R, Kang I.Mechanisms of ageing and develpoment. 2009; 130(8):509-17.

33. Najar M, Raicevic G, Fayyad-Kazan $\mathrm{H}$, et al. Mesenchymal stromal cells and immunomodulation: a gathering of regulatory immune cells. Cytotherapy. 2016;18(2):160-71.

34. Activation of human mesenchymal stem cells impacts their therapeutic abilities in lung injury by increasing interleukin (IL)-10 and IL-1RN levels. Stem cells Translational Medicine.

\section{Publisher's Note}

Springer Nature remains neutral with regard to jurisdictional claims in published maps and institutional affiliations.

Ready to submit your research? Choose BMC and benefit from:
- fast, convenient online submission
- thorough peer review by experienced researchers in your field
- rapid publication on acceptance
- support for research data, including large and complex data types
- gold Open Access which fosters wider collaboration and increased citations
- maximum visibility for your research: over 100M website views per year
At BMC, research is always in progress.
Learn more biomedcentral.com/submissions

